\title{
Challenges Faced by Nursing Students to Work with Nursing Personnel: A Qualitative Study
}

This article was published in the following Dove Press journal:

Advances in Medical Education and Practice

\author{
Hamed Rezakhani Moghaddam ' \\ Vahideh Aghamohammadi ${ }^{2}$ \\ Milad Jafari (D) ${ }^{3}$ \\ Matin Absalan ${ }^{3}$ \\ Khadijeh Nasiri $\mathbb{D D}^{4}$
}

'Health Education, Khalkhal Faculty of Medical Sciences, Khalkhal University of Medical Sciences, Khalkhal, Iran;

${ }^{2}$ Nutritional Sciences, Khalkhal Faculty of Medical Sciences, Khalkhal University of Medical Sciences, Khalkhal, Iran;

${ }^{3}$ Department of Nursing, Khalkhal Faculty of Medical Sciences, Khalkhal University of Medical Sciences, Khalkhal, Iran; ${ }^{4}$ Department of Medical-Surgical Nursing, Faculty of Medical Sciences, Khalkhal University of Medical Sciences, Khalkhal, Iran
Correspondence: Khadijeh Nasiri Department of Medical-Surgical Nursing, Faculty of Medical Sciences, Khalkhal University of Medical Sciences, Khalkhal, Iran

Tel +989372681253

Fax +9894532421979

Email Khadije.nasiri@yahoo.com
Purpose: Nursing is a practice-based discipline. Clinical education is one of the most important parts of nursing education; nurses play an important role in the learning of nursing students. This study was carried out to unveil the challenges of nursing students' learning through working with nurses.

Methods: A qualitative design was used to conduct the study in city of Khalkhal, Ardabil province, Iran. In order to collect data through purposive sampling, twenty students were interviewed using in-depth semi-structured individual techniques. Data analysis was done using MAXODA 12.

Results: Challenges of nursing students' learning were generally categorized into three main themes including inappropriate social norms, inadequate organizational atmosphere, and inadequate resources.

Conclusion: It seems that inappropriate organizational culture in the clinical setting and wrong distribution of resources will lead to disruption of student-nurse relationships and ultimately disruption of clinical education.

Keywords: qualitative research, challenges, nursing

\section{Introduction}

Nursing is a practice-based discipline. ${ }^{1}$ Nursing education consists of two practical and theoretical processes ${ }^{2}$ and its main mission is to train competent and capable nurses to have the necessary knowledge, attitude, and skills for maintaining and improving the health of society. ${ }^{3}$ One of the most important parts of nursing education is clinical education; it is very important for personal development and promotion of practical skills. ${ }^{4}$ Nursing education is closely linked to the real work environment, and nursing students always play the dual role of direct education and participation in patient caring. ${ }^{5}$ From the perspective of nursing students, the clinical learning environment includes nursing instructors and staff. ${ }^{6}$ Nurses play a vital role in the learning process of nursing students. ${ }^{7}$ The role of instructing nursing staff in nursing education is increasing and central. ${ }^{8}$ Working with an informed and education-oriented nurse can help reduce nursing students' stress levels in the clinical learning environment. ${ }^{9}$ Due to the lack of nursing staff for education, the learning experiences for nursing students may be painful. ${ }^{10}$ Generally, an environment where staff are happy and behave friendly, have a positive attitude and willingness to teach and mentor students has a positive impact on the students' learning. ${ }^{11,12}$ The results of a study conducted by Grindel et al in 2003 showed that more experienced nurses devoted more time to teaching nursing students, and less experienced nurses led 
students to carry out other responsibilities and take less time for them ${ }^{13 .}$ In a study conducted in Canada, Jones extracted the variables of friendship, closeness to students, availability, and readiness of nursing staff, and in terms of students participating in the study, nurses' closeness to the students was of the highest rank and the readiness for education was of lowest one. ${ }^{14}$ In a systematic review study conducted by Rebeiro et al in 2015, lack of time and education was the main cause of nursing students' poor relationship with nurses. ${ }^{15}$ In a qualitative study done by Mamaghani et al in Iran the results showed that educational, communication and psychological factors are important factors in students' communication with nurses. Self-Confidence was, as reported, the most important factor in establishing such a communication. ${ }^{16}$ In another study conducted in Malaysia, nurses and students reported a positive attitude toward clinical education to enhance learning. ${ }^{12}$ In a qualitative study conducted in Iran, nurses stated that although nurses have the necessary clinical skills to teach nursing students, they can negatively affect students' professionalism. ${ }^{10}$ The clinical setting is a learning environment for nursing students; they are socialized in this environment and learn the skills needed to enter the profession. ${ }^{7}$ Considering the importance of nurses' role in shaping the basic skills and professional abilities of nursing students, and the challenges created from working with nurses for the nursing students as clients of the process of training, this study aimed to explain the challenges created by working with nurses for nursing students' learning. Applying the results of this study can be effective in enhancing the educational level and increasing the students' satisfaction during the internship and reducing the stress caused by the presence of students for nurses.

\section{Methods}

\section{Study Design}

Using qualitative descriptive study, which describes the phenomena, we examined deeply the real-world experiences and behaviors of individuals and attempted to explain challenges for nursing students to work with nursing personnel.

\section{Setting and Samples}

The present study was performed on 20 senior nursing students of Khalkhal Faculty of Medical Sciences in 2018. Inclusion criteria included nursing senior students who have completed two units of training courses in the nursing management and wished to participate in the study. Students who did not attend Khalkhal at least one semester during their undergraduate were excluded.

\section{Procedure}

Although the case to case generalizations are applicable to qualitative studies, ${ }^{17}$ according to some researchers generalizability is not in main question, so qualitative researches do not use a large sample. ${ }^{18}$ These researches typically use small, non-random samples ${ }^{19}$ and study them in-depth and each person makes up a large body of information. ${ }^{20}$ In qualitative research, more emphasis is on the quality of information obtained from individuals. ${ }^{21}$ Sampling continued until meaning that no new information in the interviews was provided. Data were collected through semi-structured interviews. Two researchers (male and female) with experience in qualitative interview moderation were recruited for data collection. After explaining the personal goals and reasons for doing the research, informed consent was obtained. The interview was done with questions like whether is inevitable dealing with nurses and interacting with them in the clinic, what experience do you have of working with hospital nurses that have helped improve your clinical work? In interacting with Nurses, unpleasant experiences occur occasionally; what unpleasant experiences do you have with nurses? Nurses' interactions with patients or their companions have a profound effect on student morale; do you have any experience of the care of nurses working in the hospital? Nurses are educational models for patients and have a great impact on their behavior. Do you have any experience of the behaviors that could have been model for you? What experiences do you have of the inappropriate behavior of hospital nurses that may adversely affect your professional behavior? We proposed exploratory questions during the interview, such as explain more, have you ever encountered this situation? Can you set an example? The interviews were conducted at the hospital based on the coordination of interviewers and participants; they took between 40 to 60 minutes.

\section{Data Analysis}

We conducted twenty interviews and analyzed data simultaneously according to the Graneheim method $^{22}$ using MAXODA 12 software. This process involves open coding, creating categories, and abstraction. First, the recorded interviews along with nonverbal communications were written. The written text of the interviews, each interview and were 
reviewed several times and the initial codes were identified. The researcher also reviewed the written text line-by-line, word-for-word, and allowed the code to be created freely. In the next step, the codes that were semantically similar were placed in the same category. These categories were then classified as larger categories. The purpose of grouping was to reduce the number of classes by merging similar or non-similar classes within broader categories. Finally, the classes were abstracted at an interpretive level in order to reveal their implicit meanings (main themes).

\section{Data Trustworthiness}

The conformability and reliability criteria of Lincoln were used to ensure the accuracy and reliability of the data. ${ }^{23}$ The researcher achieved this by the long-term collaboration with the participants. After extracting the initial codes, we obtained the participants' opinions for the accuracy of the codes and interpretations; if they opposed with their opinions, they were modified and two individuals of specialty in the qualitative research controlled them and thus the required agreement were as achieved on the selected codes and classifications.

\section{Ethical Considerations}

The present study formally approved by medical ethics committee of Khalkhal University of Medical Sciences, with the ethical code of (IR.Khalums.rec.1397.006). Before the sampling, the last semester students were asked to attend a session in the faculty during which we described the purpose of the study and their collaboration in the research and asked them to determine a session for interview if they would like to participate. The quality assessment of present study was done using criteria for reporting qualitative consolidated research (COREQ-32).

\section{Results}

The mean and standard deviation of the age of the participants in the study was $22.45 \pm 1.52 .10$ participants were male and 10 were female. The results of this study revealed the challenges of students' learning by working with nurses in three themes including "inappropriate social norms", "inadequate organizational atmosphere" and "inadequate sources" as shown in Table 1.

\section{First Theme - Inappropriate Social Norms}

This theme itself includes subclasses of inadequate cohesion among nurses, mutual disrespect, megalomania, abuse, mutual mistrust, and false patterning.
Table I Challenges of Nursing Student's Learning Through Working with Nurses

\begin{tabular}{|l|l|l|}
\hline Themes & Subthemes & $\begin{array}{l}\text { Example Statements and } \\
\text { Views }\end{array}$ \\
\hline $\begin{array}{l}\text { Social norms } \\
\text { cohesion among } \\
\text { nurses } \\
\text { Mutual disrespect } \\
\text { Megalomania } \\
\text { Abuse } \\
\text { Mutual distrust } \\
\text { other, inappropriate } \\
\text { treatment with patient's, } \\
\text { companions, student } \\
\text { humiliation by nurses, putting } \\
\text { your own mistakes on } \\
\text { students }\end{array}$ \\
\hline $\begin{array}{l}\text { Inadequate } \\
\text { organizational } \\
\text { atmosphere }\end{array}$ & $\begin{array}{l}\text { Insufficient work } \\
\text { commitment } \\
\text { Lack of motivation } \\
\text { Inadequate } \\
\text { knowledge }\end{array}$ & $\begin{array}{l}\text { The repetitive and boring } \\
\text { work of nursing, low literacy } \\
\text { of nurses, lack of work ethic }\end{array}$ \\
\hline $\begin{array}{l}\text { Inadequate } \\
\text { Resources }\end{array}$ & $\begin{array}{l}\text { Low } \\
\text { of training facilities }\end{array}$ \\
\hline
\end{tabular}

\section{Inadequate Cohesion Among Nurses}

Lack of cohesion among nurses against other members of the treatment team and lack of support for each other causes problems for students' learning. On this issue, one participant says:

When nurses do not have unity among themselves, then I student cannot be among them. Nurses have never supported themselves and one of the problems is themselves. They cause their downfall and this is why our discipline is getting worse increasingly. (Participant 1)

\section{Mutual Disrespect}

Nurses' disrespect for students has led to a decrease in students' self-confidence and a loss of motivation to communicate with and learn from nurses. As nurses are part of the students' learning environment, this creates challenges for students.

'Nurses' behavior in some departments makes us reluctant to work in that ward and it becomes difficult for us to endure that ward. Nurses need to support us to become skilled, not to call us students" (Participant 3).

"We expect nurses to treat us in their dignity and as a collaborator, rather than speak to us authoritatively" (Participant 2).

\section{Megalomania}

From the perspective of the students participating in the study, priding on the nurses' skills excludes or impairs 
a students' motivation to learn as part of the clinical learning environment: "a nurse in the emergency room that shouts student's mistake in the ward and shows off by the patient" (Participant 8 ).

From the students' point of view, a lack of honest communication between nurses and students is a barrier to learning, and it makes for students uncomfortable any establishing communication. "A nurse who considers herself superior to the patient and the student cannot learn anything to no one" (Participant 12).

\section{Abuse}

Nurses' abuses of students' presence in departments and putting their work on the shoulders of students were among the challenges of students' learning in this study. Students stated that their questions would not be answered unless nurses' commands were followed. Their learning is not doing well.

When you say hello to the nurse and you want to learn from her, in fact, they are forcing us. Not everyone but some nurses have a problem with the student and think they should do their job. (Participant 5)

\section{Mutual Distrust}

According to the students participating in the present study, nurses' behaviors have led to their mistrust of students. Feedback from nurses' behavior leads to students' indifference to nurses as a source of learning and ultimately mutual distrust.

"When a nurse mistreats an elderly patient, I get upset and cannot trust that nurse" (Participant 15).

"With nurses who were well-behaved and connected we could ask questions and vice versa" (Participant 6).

\section{Wrong Patterning}

In this study, nursing caring behaviors as a part of clinical education had many positive and negative effects on nursing students, and modeling them had a significant impact on shaping students' caring behaviors. Positive influence leads to imitation of the same behavior and observations of wrong behaviors will lead to an impediment to imitate that behavior or even negative education in the student.

"If I work in a teaching hospital in the future, I will tell students what I know and if they make a mistake, I will keep it out of sight of the patient and his/her companion" (Participant 6).
“Whenever I see nurses' mistreating patients, I promise myself not to be like her. Most nurses do routine activities without scientific bases and are not a good pattern" (Participant 6).

\section{Second Theme - Inadequate Organizational Atmosphere}

This theme consisted of three categories of inadequate work commitment, lack of motivation, and inadequate knowledge.

\section{Insufficient Work Commitment}

In the view of the participants, the study of insufficient work commitment of the hospital nurses towards the patients affects the students' learning process in clinical settings and such a nurse cannot add to the students' knowledge.

"Nurses in practical education cannot help students because when a nurse does not perform its duties properly, it will also neglect in its teaching" (Participant 8).

"When I was a student, the nurse went to bed for ten nights and woke up at 7 am and I stayed up until morning and did all the work" (Participant 7).

\section{Lack of Motivation}

One of the problems reported in the study was the lack of sufficient motivation among nurses for teaching and working with students, thus affecting students' willingness to ask questions and establish learning relationships with nurses.

"When we asked questions, the nurses either don't know or are bored with" (Participant 13).

\section{Inadequate Knowledge}

One of the challenges mentioned in this study was inadequate knowledge of nurses and non-scientific nursing care routines that could not be a suitable learning model for students.

I did not learn anything useful and scientific from the nurses during the internships. Nurses in the ward cannot be practical help for the students because they are doing their routine work and most of them are not up to date in the field of nursing. (Participant 18)

\section{Third Theme - Inadequate Sources}

One of the main themes extracted is the inadequate sources that the students in this study mentioned as one of their main challenges in learning from nurses in the clinical setting. From the participants' point of view, as an 
organizational and non-individual barrier, this affects clinical education.

"The nursing work is high and the workforce is low and it has made nurses misbehave" (Participant 11).

"Weak educational facilities and physical space of hospitals also affect students' learning from nurses" (Participant 2).

\section{Discussion}

The purpose of this study was to explain the challenges of nursing students learning created from working with the nursing staff. Taken together, the findings of the present study indicate that several factors, such as inappropriate social norms, inadequate organizational atmosphere, and inadequate sources affect students' learning in relation to the nursing staff. Similarly, in a study conducted by Arkan et al, an important point for the students was that nurses have many positive and negative direct effects on the clinical learning of nursing students. ${ }^{24}$ One of the main themes of the present study is inappropriate social norms. Similarly, Curtis (2000) in their quantitative-qualitative study reported variables such as friendliness and intimacy as the most important factors affecting the relationship between students and nurses ${ }^{20}$. In another study (Bradbury-Jones), nursing students' non-acceptance as a member of the nursing team, and students' feeling of lack of respect were reported to be two clinical teaching pests, which is consistent with the findings of the present study. $^{25}$ Luanaigh, et al (2015) also reported nurses' support and Serçekuş (2016) Nurses' attitude to the clinical education as factors influencing clinical education. ${ }^{26,27}$ The results of another study also highlighted the stressfulness of students' contact with nurses in the department. ${ }^{28}$ Staff's disrespect for the students and the lack of instructor's support of students when needed, and being forced to do staff's duties have been some difficulties to which have mentioned the nursing students in the previous studies. ${ }^{25,29-33}$ However, in the success of clinical education, a positive clinical environment as an influential factor depends on the collaboration of nursing staff in the clinical environments, desired atmosphere and the acceptance of the nursing students as more youthful collaborators in the interactions ${ }^{34}$. The results of a study conducted by Baltimore and Sharif shows that inaccuracies between staff and students adversely affect the process of clinical education. $^{35,36}$ In Arkan's study, students reported that inviting nurses to participate in clinical practice as a skill exercise increased their motivation. ${ }^{24}$ In a qualitative study done by Jamshidi et al (2016), the main theme of "inefficient communication" was one of the main challenges in clinical nursing education, which is consistent with the findings of the present study. ${ }^{37}$ Other studies also emphasize the friendly relationship between nurses and students for better learning of students. ${ }^{8,12}$ Short and rotating clinical education courses seem to reduce the opportunity for student-nurses to communicate and thereby improve the likelihood of good relations, thereby affecting students' learning from nurses. This has also been addressed in Chuan's study. ${ }^{8,12}$ Therefore, we can say that ignoring professional and ethical norms by the nurses in relation to students leads to students' learning disabilities in clinical settings. In Aliafsari study, nurses' negative attitudes toward students and lack of support for the students were some reasons for nurse motivation and lack of interest in learning from nurses. ${ }^{16}$ Another major theme of the study is the wrong organizational atmosphere. In this regard, in the study done by Aieen, the inadequate relationship between the faculty and hospital was reportedly a challenge for clinical education. ${ }^{38}$ This is in line with the findings of the present study. Excessive expectations of students lead to disruption in student-nurse relationships. $^{39}$ Different levels influence relationships between students and nurses. There was also a reported lack of interest in education and concern about medical errors as two causes of poor relationships between nurses and students. ${ }^{16}$ In the study of Jamshidi et al, Nurses' lack of adequate preparation was the main theme of the study ${ }^{37}$ also in Parvan et al study; nurses stated that unfamiliarity with teaching and evaluation methods is one of the challenges of working with students, ${ }^{10}$ which is a subclass of the underlying theme of the organizational atmosphere in the present study. What is central to this section of the results is the lack of appropriate organizational mechanisms for the students' clinical learning from nurses, which has led to the creation of major challenges in students' clinical learning. In general, the organizational atmosphere is influential in any system, but the organizational atmosphere governing nursing clinical education systems can lead to the training of non-professional and noncommitted nurses because of its direct impact on students' learning experiences, so it is important to modify the status quo. Several studies have identified nurses as role models for student. ${ }^{10,40,41}$ Inadequate sources are other major themes of study. In his study, Arkan reports that nurses cannot allocate enough time to educate students because of the multitude of patients they are responsible 
for $^{24}$; this is consistent with the findings of the present study. Also in the study of Chuan, students stated that during times when nurses are overworked, learning opportunities are missed because nurses prefer to spend their time doing their tasks, even when such situations provide a good opportunity to practice short methods for doing tasks quickly. ${ }^{12}$ In the study of Aliafsari, high workload and insufficient time were reportedly some factors affecting student-nurse's communication. ${ }^{16}$ This is consistent with the underlying theme of inadequate sources in the present study.

\section{Limitations}

One limitation of the present study is the non-use of experiences of nurses and nurse managers regarding the challenges of students' learning. Further studies are recommended on the nursing managers, nurses and even clinical educators to identify the challenges and factors affecting the relationship between nurses and students. Also, the present study did not cover all students around the country.

\section{Conclusion}

Taken together, the findings of this study indicate that nursing students face numerous challenges for learning in clinical settings. Experience of inappropriate social norms in the clinical setting, lack of proper hospitalization for students' learning from nurses, and nurses' inadequate time due to lack of nursing staff to meet the educational needs of nursing students will lead to disruption of student-nurse relationships and ultimately disruption of clinical education. Since nursing staff is one of the main pillars of the clinical environment for nursing students, so knowing the obstacles and challenges by identifying these factors can help to improve students' learning in clinical settings.

\section{Acknowledgments}

We thank Khalkhal University of Medical Sciences for funding this research. We hereby declare our gratitude to the all participants.

\section{Disclosure}

The authors report no conflicts of interest in this work.

\section{References}

1. Wang $\mathrm{H}, \mathrm{Li} \mathrm{X}, \mathrm{Hu} \mathrm{X}$, et al. Perceptions of nursing profession and learning experiences of male students in baccalaureate nursing program in Changsha, China. Nurs Educ Today. 2010;31(1):36-42.
2. Bourbannais FF, Langford S, Giannantoni L. Development of a clinical evaluation tool for baccalaureate nursing students. Nurs Educ Pract. 2008;8(1):62-71. doi:10.1016/j.nepr.2007.06.005

3. Li YS, Chen PS, Tsai SJ. A comparison of the learning styles among different nursing programs in Taiwan: implications for nursing education. Nurs Educ Today. 2008;28(1):70-76. doi:10.1016/j. nedt.2007.02.007

4. Saaranen T, Vaajoki A, Kellomäki M, Hyvärinen ML. The simulation method in learning interpersonal communication competence-experiences of masters' degree students of health sciences. Nurs Educ Today. 2015;35(2):8-13. doi:10.1016/j.nedt.2014.12.012

5. Allan TH, Smith P, O'Driscoll M. Experiences of supernumerary status and the hidden curriculum in nursing: a new twist in the theory-practice gap. J Clin Nurs. 2011;20(5-6):847-855. doi:10. 1111/j.1365-2702.2010.03570.x

6. Saarikoski M, Warne T, Kaila P, Leino-Kilpi H. The role of nurse teachers in clinical practice: an empirical study of Finnish student nurse experiences. Nurs Educ Today. 2009;29(6):595-600. doi:10. 1016/j.nedt.2009.01.005

7. Kilcullen NM. Said another way: the impact of mentorship on clinical learning. Nurs Forum. 2007;42(2):95-104. doi:10.1111/j.17446198.2007.00073.x

8. Lewin D. Clinical learning environments for student nurses: key indices from two studies compared over a 25 -year period. Nurs Educ Pract. 2007;7(4):238-246. doi:10.1016/j.nepr.2006.08.002

9. Matsumura G, Callister L, Palmer S, Cox A, Larsen H. Staff nurse perceptions of the contributions of students to clinical agencies. Nurs Educ Perspect. 2004;25(6):297-303.

10. Parvan K, Shahbazi SH, Ebrahimi H, et al. Nurses' lived experience of working with nursing students in clinical wards: a phenomenological study. J Caring Sci. 2018;7(1):41-45. doi:10.15171/jcs.2018.007

11. Papastavrou E, Lambrinou E, Tsangari H, Saarikoski M, Leino-Kilpi H. Student nurses experience of learning in the clinical environment. Nurs Educ Pract. 2010;10(3):176-182. doi:10.1016/j.nepr.2009.07.003

12. Chuan OL, Barnett T. Student, tutor and staff nurse perceptions of the clinical learning environment. Nurs Educ Pract. 2012;12(4):192-197. doi:10.1016/j.nepr.2012.01.003

13. Grindel C, Patsdaughter C, Medici G, Babington L. Research for practice: adult-health/medical-surgical nurses' perceptions of students' contributions to clinical agencies. Med Surg Nurs. 2003;12 (2):117-123.

14. Jones SH. Nursing Students' Perceptions of Working with Staff Nurses. A Thesis Submitted in for the Degree of Master of Nursing. Bozeman, Montana: Montana State University; 2010.

15. Rebeiro G, Edward K, Chapman R, Evans A. Interpersonal relationships between registered nurses and student nurses in the clinical setting - a Systematic integrative review. Nurs Educ Pract. 2015;35 (12):1206-1211.

16. Mamaghani EA, Rahmani A, Hassankhani H, et al. Effective Characteristics of Iranian Nursing Students in Their Relationship with Clinical Nurses. J Caring Sci. 2019;8(3):173-179. doi:10. $15171 /$ jcs.2019.025

17. Firestone WA. Alternative arguments for generalizing from data as applied to qualitative research. Educ Res. 1993;22(4):16-23. doi:10. 3102/0013189X022004016

18. Wood G, Haber J. Nursing Research. Methods, Critical Appraisal and Utilization. 6nd edition G LoBiondo ed. Mosby; 2017:470.

19. Oskoei F, Peyravi H. Qualitative Research in Nursing. Tehran: Publication of Iran University of Medical Sciences and Health Services; 2015. [In Persian].

20. Curtis S. Approaches to sampling and case selection in qualitative research: examples in the geography of health. Soc Sci Med. 2000;50 (7-8):1001-1004. doi:10.1016/S0277-9536(99)00350-0

21. Burns N, Grove S. The Practice of Nursing Research (Appraisal, Synthesis and Generation of Evidence). Sixth edition ed. Saunders Publication; 2009. 
22. Graneheim UH, Lundman B. Qualitative content analysis in nursing research: concepts, procedures and measures to achieve trustworthiness. Nurs Educ Today. 2004;24(2):105-112. doi:10.1016/j.nedt.2003.10.001

23. Polit DF. Essentials of Nursing Research: Methods, Appraisal, and Utilization. 3rd ed. Philadelphia: Lippincott Williams \& Wilkins; 1993.

24. Arkan B, Ordin Y, Yilmaz D. Undergraduate nursing students' experience related to their clinical learning environment and factors affecting to their clinical learning process. Nurs Educ Pract. 2018;29:127. doi:10.1016/j.nepr.2017.12.005

25. Bradbury- Jones C, Sambrook S, Irvine F. The meaning of empowerment for nursing students: a critical incident study. J Adv Nurs. 2007;59(4):342. doi:10.1111/j.1365-2648.2007.04331.x

26. Luanaigh PO. Becoming a professional: what is the influence of registered nurses on nursing students' learning in the clinical environment. Nurs Educ Pract. 2015;15:450-456. doi:10.1016/j. nepr.2015.04.005

27. Serçekuş P, Başkale H. Nursing students' perceptions about clinical learning environment in Turkey. Nurs Educ Pract. 2016;17:134-138. doi:10.1016/j.nepr.2015.12.008

28. Papp L, Markkanen M, Von -bonsdorff M. Clinical environment as a learning environment: student's nurse's perceptions concerning clinical learning experiences. Nurs Educ Today. 2003;23 (4):262-268. doi:10.1016/S0260-6917(02)00185-5

29. Khadivzadeh T, Farzi F. Investigation of strengths and weaknesses of clinical teaching from nursing and midwifery student's in Mashhad. J Med Educ. 2003;10:67.

30. Jackson D, Mannix J. Clinical nurses as teachers: insights from students in the first semester of study. J Clin Nurs. 2001;10 (2):270-272. doi:10.1046/j.1365-2702.2001.00471.x

31. Midgley K. Pre-registration student nurse's perception of the hospital learning environment during clinical placements. Nurs Educ Today. 2006;26(4):338. doi:10.1016/j.nedt.2005.10.015
32. Chan DSK, Ip WY. Perception of hospital learning environment: a survey of Hong Kong nursing students. Nurs Educ Today. 2007;27:677-684. doi:10.1016/j.nedt.2006.09.015

33. Newton JM, Billet S, Ockerby CN. Journeying through clinical placements: an examination of six student cases. Nurs Educ Today. 2009;29(6):630-641. doi:10.1016/j.nedt.2009.01.009

34. Hickey M. Preceptor perceptions of new graduate nurse readiness for practice. J Nurs Staff Dev. 2009;25(1):35-41. doi:10.1097/NND.0b0 $13 \mathrm{e} 318194 \mathrm{~b} 5 \mathrm{bb}$

35. Baltimore JJ. The hospital clinical preceptor: essential preparation for success. J Contin Nurs Educ Today. 2004;35(3):133-140. doi:10.39 28/0022-0124-20040501-10

36. Sharif F, Masoumi S. A qualitative study of nursing student experiences of clinical practice. BMC Nurs. 2005;4(1):120-129. doi:10.11 86/1472-6955-4-6

37. Jamshidi N, Molazem Z, Sharif F, Torabizadeh C, Najafi Kalyani M. The challenges of nursing students in the clinical learning environment: a qualitative study. Sci World J. 2016;2(21):1-7. doi:10.1155/ 2016/1846178

38. Aieen F, Hasheminia AM, Moghadasi J.Preceptors and student's experiences on the implementation of preceptorship model in clinical practice. JNE. 2012;1(1):25-37.

39. Nolan G, Ryan D. Experience of stress in psychiatric nursing students in Ireland. Nurs Stand. 2008;22(43):35-43. doi:10.7748/ns2008.07. 22.43.35.c6583

40. Huybrecht S, Loeckx W, Quaeyhaegens Y, De Tobel D, Mistiaen W. Mentoring in nursing education: perceived characteristics of mentors and the consequences of mentorship. Nurs Educ Today. 2011;31 (3):274-278. doi:10.1016/j.nedt.2010.10.022

41. Valizadeh L, Zamanzadeh V, Gargari RB, Ghahramanian A, Tabrizi FJ, Keogh B. Pressure and protective factors influencing nursing students' self-esteem: a content analysis study. Nurs Educ Today. 2016;36:468-472. doi:10.1016/j.nedt.2015.10.019
Advances in Medical Education and Practice

\section{Publish your work in this journal}

Advances in Medical Education and Practice is an international, peerreviewed, open access journal that aims to present and publish research on Medical Education covering medical, dental, nursing and allied health care professional education. The journal covers undergraduate education, postgraduate training and continuing medical education including emerging trends and innovative models linking education, research, and health care services. The manuscript management system is completely online and includes a very quick and fair peer-review system. Visit http://www.dovepress.com/testimonials.php to read real quotes from published authors.

Submit your manuscript here: http://www.dovepress.com/advances-in-medical-education-and-practice-journal 